IIMI Working Paper No. 4

\title{
SUSTAINABILITY IN IRRIGATED AGRICULTURE
}

by

\author{
Mark Svendsen
}

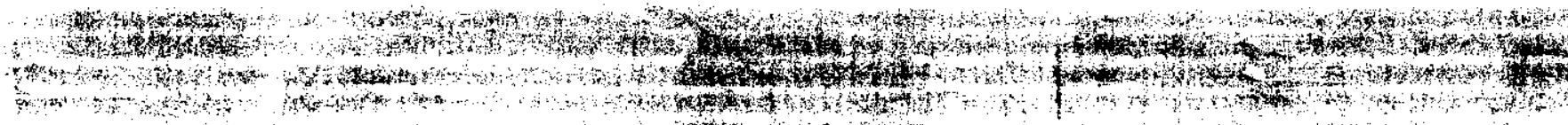

BEFEREXCE

ONLY

-.MI

WP $\mathrm{N}$

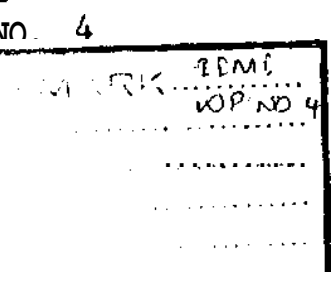

$1+28053 \ldots$

INTERNATIONAL IRRIGATION MANAGEMENT INSTITUTE 
IIMI Working Paper No. 4

SUSTAINABILITY IN IRRIGATED AGRICULTURE

by

Mark Svendsen
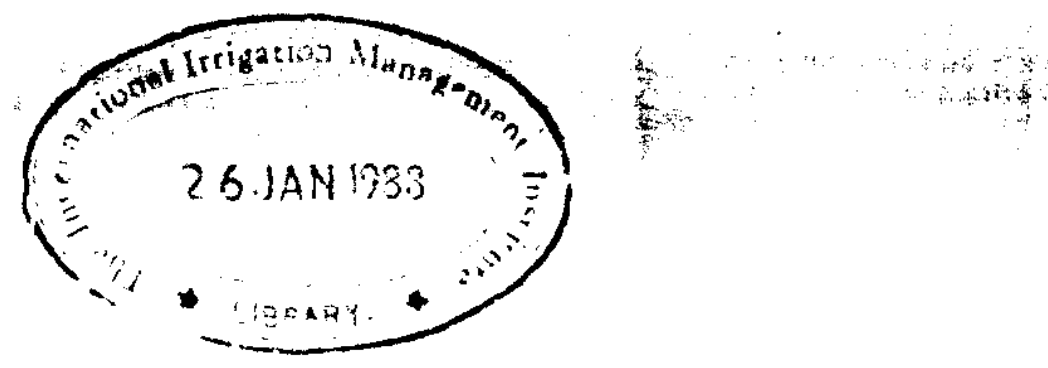

IIMI Pub 87-26 (December)

IIMI Working Papers are produced for discussion and should not be quoted. Although the contents have been reviewed by IIMI staff who are knowledgeable in the subject area, Working Papers are only lightly edited and generally present preliminary results of ongoing research. Comments are invited and should be sent directly to the author at the International Food Policy Research Institute IFPRI-II:1I Liaison Office, 1776 Massachusetts Ave, NW, Washington DC 20036. USA.

This Working Paper was published by:

International Irrigation Management Institute Digana Village via Kandy. Sri Lanka.

Telephone (08) 74274, 74334. 74251.74265, * 74268; IDD 32491 ; Telex 22318 IIMIHO CE 


\section{TABLE OF CONTENTS}

Introcustion ...................... 1

Characteristics of Sustainability. . . . . . . . . . 2

A Systems Concept . . . . . . . . . . . . . . . . 2

Discontinuities.................. . 2

Externalities ................ . . 3

A Collective Problem . . . . . . . . . . . . . 4

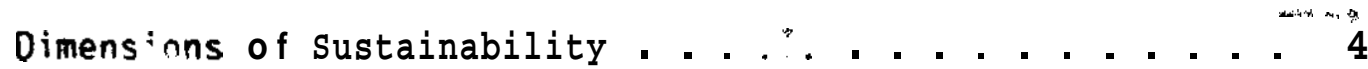

St tain What?................. 4

Sustain How Long?. . . . . . . . . . . . . . . 5

Sustainability and Irrigation . . . . . . . . . . . . -

Irrigation and Agricultural Growth . . . . . . . . . 7

Self-sustaining Systems .............. . 8

Irrigation and the Resource Base . . . . . . . . 10

Conclusions .................... . . . . . . 


\title{
SUSTAINABILITY IN IRRIGATED AGRICULTURE ${ }^{1}$
}

\author{
Mark Svendsen 2
}

\section{Introduction}

While not a new issue ${ }^{3}$. gricultural sustainability is a very topical concern in many quarters. The World Bank held a 2-day in-house symposium on the topic n January of 1987, and the Consultutive Group on International A9 i rultural Research (CGIAR) is devoting considerable attentio to the topic. Its Technical Advisory Comittee (TAC) has re ly prepared a review of future strategies and priorities for te CGIAR which gives prominent place to "sustainability" in boti the articulation of the overall goal of the CGIAR and in the first of 8 objectives addressing this goal. The TAC is also exploring ways in which the International Agricultural Research Centers (IARCs) can more fully address sustainability questions.

Lanentably, there is 'a' great. : deff of anbiguity in much of the afscussion that has so far taken place on "sustainability." Admittedly, it is a diff: :ult concept to specify, though its strong affective appeal, like that of puppies and sunsets, continues to compel attention in spite of its vagueness. There may well be a certain trendiness or fadishness to it now as well which, while

1This paper grew out of thinking done in preparation for a meeting of USAID irrigation project managers held in Karachi, Pakistan in January 1987 and benefits greatly from the discussions which occurred there. I am also indebted to colleagues at IFPRI who suggested ideas and offered helpful criticism, particularly Gunvant Desai; Bruce Stone, and Steve Vosti.

* Research Fellow, International Food Pol icy Research Institute and Resident Scientist, Interr tional Irrigation Management Institute

${ }^{3}$ peter oram, in introducing a working paper on the topic prepared for the TAC of the CGIAR, suggests that following systems, shifting cultivation, crop rotation, rotational grazing, nomadism, transhumance, terracing, banding, check dams, drainage systems and the use of dung, compost, lime, marl, and other soil amendments constitute examples of the longstanding importance farmers attach to sustainability. 
drawing attention to the set of problems it represents, can just as quickly strip it of legitimacy and consideration as the spotlight shifts. However, continuing population pressure on rne world's productive resource base insures that the substantive issues involved will, in fact, remain relevant and important over the foreseeable future.

This short paper attempts to bring some focus to the discussion, particularly as it concerns irrigated agriculture, by suggesting some central features which characterize the notion of "sustainability" and by suggesting several ignificant dimensions which help to define it. In the particular ...se of irrigated agriculture, three broad categories are suggested or organizing issues for discussion.

\section{Charac stics of sustainability}

\section{A Systems Concept}

Sustainability is a systems concept--applying to a set of elements which interact in some regular and interdependent fashion. In the present context, it refers to productive systems--those generating outputs valued and used by people. Moreover, sustainability is, by its nature (and as follows from the definition above) a feature of

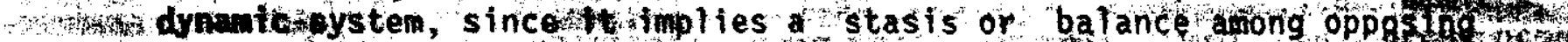

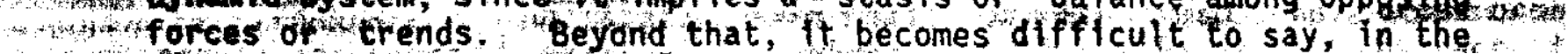
abstract, just what sustairbility is. Rather, the tendency is to say what it is not, by characterizing its negative image--the situation that prevails or will prevail when a syrtem lacks sustainability. Although not completely satisfying, such a characterization is better than none, and three features distinguishing it are suggested below.

\section{Discontinuities}

The first of these is an accelerating pace of negative change leading to discontinuities in "loss, cost, and benefit functions." 4 Such a situation would occur when a farmer decides to stop planting and abandon a field or farm. The upshot of this is that once such a point is reached, it becomes impossible or inordinately costly to reverse the direction of the change and return to a more favorable equilibrium.

An example is found in rising wateliables in irrigated areas. As the level of the watertable moves toward a point about 3 meters below the surface, sometimes from great depths, little impact is felt on either the costs of production or the benefits derived. Between 3 and 2 meters depth, in fine textured soils. water begins to move upward into the crop root zone through capiliary action and with a further

${ }^{4}$ This notion and the one tiat follows relating to externalities were suggested to inn by Bruce Store of IFPRI. 
rise in the water table will reach the surface by this means. If the subsurface water involved is saline, production drops quickly and land may go out of production within a few seasons.

Another more cataclysmic example is contained in the scenario that has globai temperatures rising due to in increase in $\mathrm{CO}_{2}$ concentrations in the atmosphere, resulting in melting Icecaps, rising sealevels, inundation of coastal dieas (New Orleans, for example) and dramatic worldwide shifts : limatic patterns and, consequently, in patterns of agrlcu al activity. The discontinuities here are obvious.

\section{Externalities}

The second feature, perhaps the most pervasive one characterizing the sustainability issue, is its association with "intergroup and intertemporal externalities. "5 This means simply that the activities. of one group of people have some unintended impact, other positive

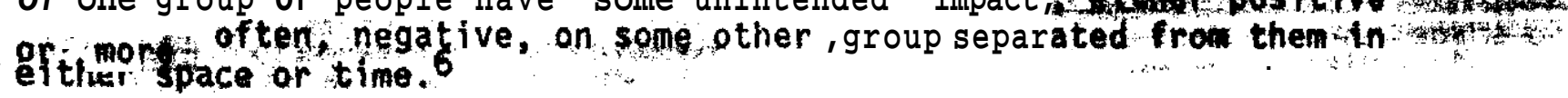

This is the case, for example, when overexploitation of a watershed lying above an irrigation reservoir results in rapid ailtation of the reservoir, significantly reducing its storage capacity anc the amount of dry season water available to farmers served by it. Moreover, the effective lifetime of the reservoir is shortened correspondingly, leading toward "discontinuity" and, most would agree, a problem of sustainability.

To take a more general example, the combustion of high-sulfur coal in Midwestern power plants is widely believed to reduce the productivity of Canadian forest and aquatic resources. Given the time it takes to bring a newly replanted forest to maturity (even if the root cause of the problem were eliminated) and the wide-spread impact of the acid rain externality, a discontinuity is a clear and $19.21 y$ possibility,

The forestry example is apt also because of the common use, in that industry, of the term "sustainable yield"--meaning the amount of timber which can be harvested in a given year without reducing output in subsequent years. The issue of sustainability, and its absence, is clearly in evidence here.

The temporal dimension of externalities is iniportant as well. When applied to natural resource issues, it becomes the question of today's exploitation foreclosing options for our children's children-

\section{${ }^{5}$ See footnote 3 .}

6 Although resiricted to human activity he 9 , one could presumably apply the same concept to natural ecosystens, food chafns, etc., though wtthout economic valuation. 
-probably the most gripping manifestation of the sustainability question. Abandoned salinized land; silted-in reservoirs which cannot be cleaned, removed or replaced; acidified lakes; pesticidelaced groundwater; and aquifers depleted of ancient "fossil"water are examples. There are a number of reasons and historical examples that should keep us from becoming too alarmist about these things, but there are also serious and valid reasons for concern.

It should be noted in passing that there are positive e: . - rnalities as well as negative ones. High water tables resulting $f$ om surface irrigation, if they are not saline and if they do $\cdots+$ lead to waterlogging of the crop root zone, provide a sub-surfa oservoir which can be readily tapped by individuals with small psets or even by hand to serve as a cheap source of supplementar irigation water. In general, however, the externalities we consider in connection with sustainability are the negative ones.

\section{A Collective Problem}

The third feature, following from the second is the collective

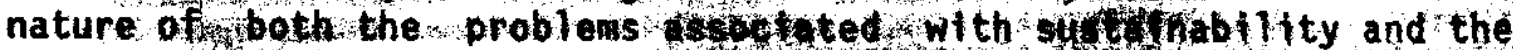

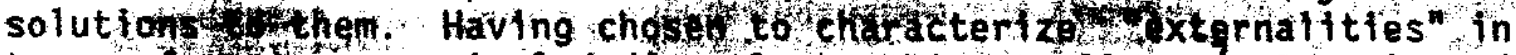
terms of fofolos one is led directly to this corollary. $E$ amples of this are not difficult to think of.

The implication for action to forestall threats to the sustained operation of systems is that actions affecting the collectivity must either be undertaken by (a) a public agency with sufficient authority to induce or compel changes in individual or institutional behavior, or (b) collectivities that choose to act, for whatever reason, in the common interest of the membership as a whole, perhaps at some cost to individual members. 8

\section{Dimensions of Sustainability}

Sustain What?

It is now time to ask a critically important qusstion--what is it that we are concerned about sustaining? Thus far, the examples used have all related to sustaining the integrity or productivity of a natural resource--water. forests, Fisheries, and so on. This corresponds to the perspective that is commonly taken on the issue,

7 Though externalities can also arise from the actions of individuals acting alone, effects are not usually of sufficient magnitude to threaten the sustainability of associated systems.

8If the system failure (discontinuity) has already occurred, it is far more likely that governmental action will be required, $r a \cdot t$ er than grass-roots collective action, given the much larger costs . at will usually be involved in restoring it to functional viability. 
though it is not always said explicitly. Other kinds of systems, however, can also share (or lack) the attribute of sustainability. The financial position of the US Government, for example, may not be a sustainable one over the long run, given the yawning gap between receipts and expenditures.

It is useful to recall that "sustain", as a verb, is a trans ive verb that requires a direct object to complete its meaning. Thu-, it is important, necessary even, to be clear and specific about that object. It is here, it seems to me, that a great deal of $\operatorname{con}^{-2}$ in and ambiguity arises. Even when the topic is restricted to the Im of econoniic development, sustainability can be taken as referri; to a wide range of items--a pilot innovation, such as a new agriculisal extension system; a particular donor-funded project, especially after the donor leaves; a piece of infrastructure, such as an irrigation system or a road network; a particular level of investment or growth; a physical resource base, as already discussed; a genetic resource base; yield levels; and a host of others.

Sogolyopreferred "difoctobjects" from anohg the items on this 15 107 thot be possible, or even desirable, since much of tie richess of sustainability as a concest is a result of its multifaceted character. Nevertheless, ambiguity in discussing it, where the nature of the objective is not made clear, is not usually very productive.

To proceed much further in this direction, it is necessary to narrow our focus. In moving from more general consideration of "sustainability" in agricultural systems to its application to the irrigated agricultural sub-sector, we can be more specific about both the nature of the issues and the shape of possible solutions. Three broad problem areas relating to the "sustainability" of irrigated agriculture are discussed toward the end of the paper.

\section{Sustain How Long?}

The second major dimension of sustainability in agricultural systems is its tinie horizon. This is critical, since, as in the reservoir siltation example above, what is normal and expected, i.e. a reservoir with a design lifetime of 80 years silting up after 80 years, becomes a serious sustainability problem if rapid siltation results in an actual lifetime of 40 years. An irrigation system which requires rehabilitation after 5 years has a sustainability problem. One that functions well for thirty years does not. Thus sustainability is, in large part, a question of accordance with our expectations regarding longevity.

IF, as a mental exercise, one were to set up a simple time scale for expectations and sustainability, one might choose the agricultural season as the minor unit of time, the "minute" 35 it were, since sustainability over a shorter period has little meaning. The "hour".: might be the duration of the human generation. The latter choice, 
builds directly on the concern we have with the future we hand over to our heirs and has the added advantage of coinciding roughly with the economically-useful lifetimes of irrigation systems and other pieces of infrastructure that we calculate for project planning purposes. 9 This is not, by any means, to suggest one generation as a normative standard for sustainability, but simply that in many cases, we can reckon sustainability in periods consisting of a small number of generations. For although we can certainly think, and to some extent plan, in terms of periods of several generations, events centuries or millennia in the future lie beyond rational speculation in the realm of belief.

In addition then to specifying what it is we wish to sustain, we must also be clear on how long we wish it to last. There are, of course, some things that we would have last indefinitely--things like the earth's oxygen-rich atmosphere, the ozone blanket that screens certain kinds of harmful radiation from us and the diversity of our biotic genepool. Other things, such as physical infrastructure, we assign a definite (and somewhat arbitrary) lifetime to. Still others we are highly uncertain about, as, for example, the importance that

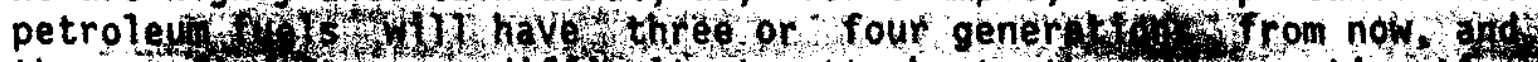

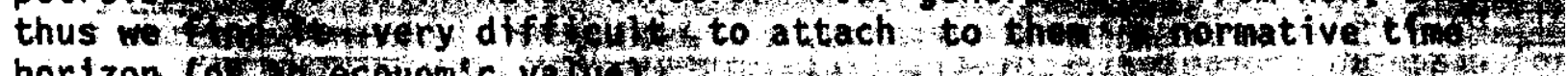

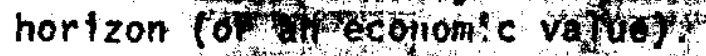

One important implication extending from this discussion is that sustainability problems are not fundamentally physical resource problems or technology problems, but institutional ones. Over a period of one or a few seasons, no piece of infrastructure, no technology, is stable or sustainable without institutions to operate repair, adapt, and maintain it. Institutions are flexible, can change,.. evolve, and respond. Technological hardware cannot.

Furthermore, since we have defined sustainability problems in agriculture as collective problems, we are led quite directly to institutions--users groups, special resource (e.g. irrigation) districts, regulatory bodies, government line departments, lobbies, professional associations, special interest groups, and the like--as the keys to sustainability.

A second implication, one that serves to tie together the dimensions of "object" and "duration", is that we should select the objects of our analysis in such a way that some durability and generality are built into them. This means framing them in terms of systems for which we have expectations regarding both performance and duration

${ }^{9}$ At any reasonable discount rate, the current value of the benefits stemming from the investment becomes relatively insignificant after 25 or 30 years. At a discount rate of $10 \%$, $\$ 1$ received 30 years from now is worth about a nickel today. Coincidentally, assuming two agricultural seasons in a year and 30 Year generations ylelds a sixty minute "sustainability" hour. 
and which include both technological and institutional domains. This may mean beginning at a higher level of generality and moving downward to the kinds of questions relating to a specific resource or technology that we are more used to asking.

In the following discussion, an attempt has been made to suggest three such "higher-level'' questions for consideration with respect to irrigated agriculture.

\section{Sustainability and Irrigation}

\section{Irrigation and Agricultural Growth}

The first broad area relates to the central role that irrigation development has played in increasing agricultural output in many developed and developing countries. Examples as diverse as the United States, India, the Philippines, Egypt, Zimbabwe and Nepal can be mentioned. The importance of irrigation In realizing the productive potential inherent in improved wheat and rice varieties-both through its direct yield and cropping Index effecis and through

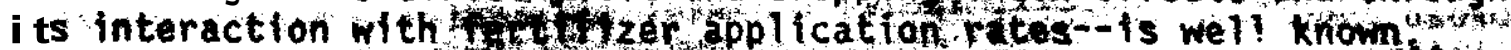
$\therefore$ w

Untll quite recently, most growth in "Irrigated agricultural -production has come through expansion of area irrigated. In Asia, this era Is drawing to a close as the most accessible resources are exploited, and in Africa extremely high irrigation development costs similarly constrain creation of new capacity. However there remains scope for development of new command in both regions, although both face similar problems in justifying such development on economic grounds.

The second source of irrigation-related growth in production--more effective utilization of already-developed water sources--is somewhat more complicated. In some cases, it may be possible to augment existing supplies. Often, however, irrigation will have to make do with less water rather than more as competing users such as municipalities increase their higher-priority demands. This is already happening in places as diverse as Taail Nadu, Central Java, and the Western United States.

The sustainability of past rates of growth in production and productivity in the face of an anticipated decline in the rate of new system construction and declines in the water available to existing systems is an issue of considerable importance. Some tools and mechanisms which blend (1) physical improvements, (2) changes in management structures and practices, and (3) policies governing the subsector are available to address this challenge. Howevei, although experiments applying differing combinations of these factors have been undertaken, often in an "action research" mode, there is not yet a clear understanding of, or agreement on, the sets of measures which are most appropriate in particular settings, or on the magnitude of their impacts. 


\section{Self-Sustaining Systems}

Second is the issue of the sustainability of the functioning of irrigation systems themselves. A number of recent and not-so-recent studies and evalnations have highlighted problems of shortfalls in area served by irrigation systems, lower than expected productivity, allocational disparities between head and tail-enciers, large recurrent cost burdens on government, and' overrapid system deterioration and the need for frequent system rehabilitation. Sustainability in this sense is an issue that profoundly affects not only the viability and productivity of existing systems but the economic rationale for the development of new irrigation command as well.

To address this seemingly disparate set of problems, an equally disparate set of remedies might be proposed. And while problems can and are being addressed in this fashion, it is also useful to look more broadly at the policy and institutional matrix in which these problems operate. This matrix is defined. in part, by resource

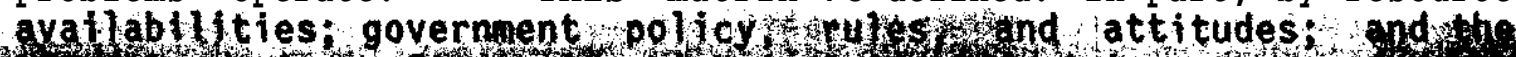

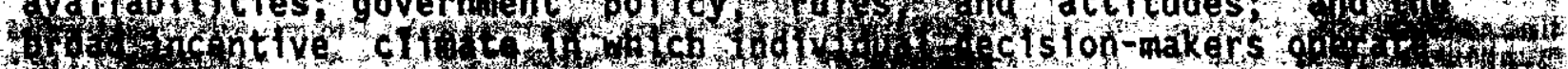

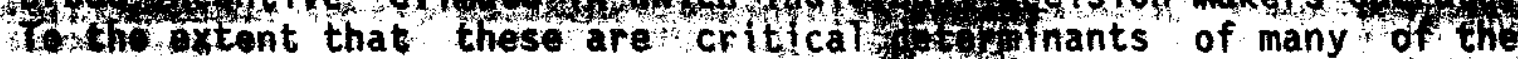
problems indicated above, as 1 belfeve they are, they become .essential features of an analysis of sustainability in irrigated agriculture. The following paragraphs outline the main features and relationships of a model describing this incentive climate surrounding both irrigation agency personnel and farmers and suggest points of possible intervention.

Along with the expansion in irrigated area in most countries, has come a rising recurrent cost burden on national or state treasuries. This is so because in the vast majority of cases, recurrent costs are not funded from irrigation revenues, which are inadequate in any case, but from the general revenues of the state. Moreover, water is paid for by its users on an administratively-determined basis that usually bears no direct relationship to the quantity of water used. And even where there is some relationship between rate structures and quantities of water delivered, the farmer usually has little or no control over the volume or timing of those deliveries, rendering any incentive effect on him moot. In such a situation, cost recovery is low and financial incentives do not operate on either the irrigation agency or on farmers to encourage careful or judicious use of water. Raising water charges has virtually no effect on operational efficiency in this type of situation.

To break out of this cycle, it is necessary to reassess the basis on which irrigation agencies operate, raise their revenues, assess their institutional performance, reward and promote their staff, and share responsibility with farmers. Interesting recent evidence from the Philippines and innovative but aborted experimentation in Sri Lanka, as well as several recent cross-sectional studies on irrigation system cost recovery, have suggested that there are ways 
public irrigation systems on a more self-sustaining footing, decreasing costs of operation, increasing revenues from direct beneficiaries, and providing incentives for more effective management on the part of irrigation bureaucracies. This is a most important area for further research.

In many ways such organizational reorientation and restructuring is crucial to sustained success in many of the problem areas afflicting : blic irrigation systems. Unless systems of accountability can be :stablished linking the two major participant groups In the Irrigation enterprise--public irrigation departments and farmers-$n$ there is 1ittle reason to expect system-oriented problem-solving avior on the part of either. Furthermore, continued growth in iernment outlays for Operations and Maintenance (O\&M), and in the ap between revenues and expenses, will create strong pressure for reductions in operating budgets (as opposed to personnel budgets, which are far more resistant to reduction) and for deferred maintenance. In such a situation, the required improvements in operating efficiencies will be difficult if not impossible to achieve.

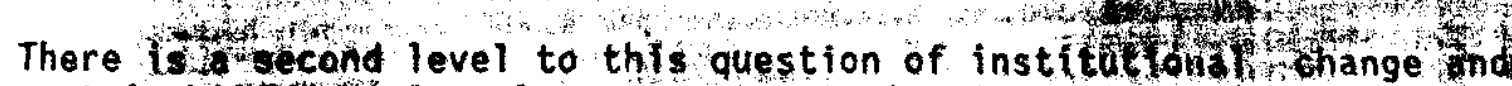
s'stainabifity. In a iarger sense, irrigation agencias must develop tr: capacity to manage the adaptive change process themselves. One sure companion to economic development is the increasing pace of change. Irrigation systems designed 50 or even 15 years ago are today typically called upon to perform different functions and satisfy different objectives than those they were designed for. To adapt to changing needs requires a capacity to assess changed conditions and needs and develop appropriate response strategies--a process which most irrigation agencies are ill-equipped to instigate and manage.

From a longer-range perspective, the fundamental "solution" to the problem of sustainability is the development of a set of institutions which work together to provide the capacity to deal with change. Irrigation agencies must play a leading role in this, but cannot be expecte: to carry out all of the specialized study, training, and advisory functions involved themselves. Thus sustainability is, at its roots, an institutional problem that extends to include the irrigation agency, farmers, and supporting organizations.

\section{Irrigation and the Resource Base}

A third set of issues relates to the interactions of irrigation schemes with their (physical and human) environments. Included here are the impacts that related systems, such as livestock and agroforestry systems, in upper watersheds have on irrigated agricultu-e downstream, as well as the negative externalities of irrigatine development and operation themselves on populations and resource zases. Both types of effects degrade physical resources that are inite in extent, and can lead to serious discontinuities in 
benefit streams and cut short productive lifetimes of major infrastructural investments.

of all of the undesired development, salinity and

consequences of large-scale irrigation waterlogging are probably the ones most frequently mentioned in the context of irrigation system sustainability. Estimates of their extent around the world vary, but they constitute a major and undeniable serious threat to the producti 3 capacity and long-run sustainability of a large number of irrigatin systems.

In some :uations, there is no alternative to the installation of extens jurface or tile drainage systems in previously irrigated areas. lajor drainage programs, for example, are underway in extensi 2 irrfgated areas of Egypt and Pakistan's Sind Province. In other cises though, and as a complement to the installation of drainage systems, there are a number of non-structural measures which can have a significant impact on alleviating problems of waterlogging and salinization.

Technical constraints are usually not in fact the most intractable

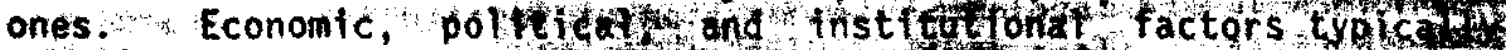

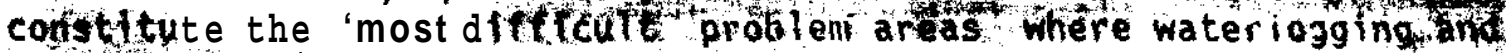
satinizat on (W\&S) becone threats. Major difficulties reiate to the delayed onset of effects which provides a false sense of well-being, the collective nature of many of the solutions, the restricted constituencies supporting remedial programs, and the high costs both of constructing drainage systems and operating and maintaining them.

To the extent that W\&S problems stem from over-irrigation, which is a major causative factor, the measures outlined above that reduce the incentive to deliver and apply excessive amounts of water also alleviate W\&S problems. Additionally, systems which transfer at least a.share of the costs of treating the problems to those whose actions influence their creation can also be effective.

One of the most interesting approaches to this difficult problem lies in the creation of farm-level incentives for water table control. An example is the case of the Punjab in Pakistan where 150,000 private tubewells installed in the past 15 years to supplement canal water deliveries have had an important impact on controlling rising regional water tables. The search for ways to stimulate private investment in water table control and other non-structural ways of dealing with resultant W\&S problems deserves considerably more attention than they are currently receiving.

In the best of circumstances, as its proponents claim. irrigation development captures and puts to productive use a renewable resource of enormous potential benefit which would otherwise have little economic utility. Indeed, the food security of many nations depends critically on he productivity of their irrigated lands. At its worst, critics argue, it buries fertile valley bottoms beneath 
millions of cubic meters of water, displaces thousands of people, and leaves saline deserts in its wake. Truth is present in both statements. But given our dependence on irrigation to feed the global population, the alternatives to consider are not whether or not to irrigate, but how irrigation can be done in a sustainable manner.

\section{Conclusions}

To some, the attention $n$ eing paid to "sustainability" represents effort diverted from , productive work directed at the same problems under more trad; onal typologies. While It is true that most of the issues subtended under the sustainability heading are old issues, there is value in reorganizing and reconsidering from time to time to stimulate new ways of considering the problems and avoiding hackneyed analysis and solutions.

The traditional focus of sustainability inquiries has been the natural resource base supporting the particular sectoral area of 1 trestas interest. A more useful framework of analysis treats a resource-. " based productive system, $\boldsymbol{s}$ explicit about what is to be sustained, and is explicit about the cime period of interest. It also includes in its purview the controlling policies and institutions in the specification and analysis, for these are the living evolutionary adjuncts of the exploitative technology.

In respect of irrigated agriculture, three broad topical areas are suggested as a first-level dichotomy of sustainability issues. These are first of all, the sustainability of past rates of growth in production and productivity. This brings us beyond a focus on a particular irrigation system or system type and ties sustainability firmly to the economy as a whole. It also allows a wider range of tradeoffs between, for example, the pace of new system construction and the long-term rates of change in production for existing irrigation schemes.

The second area is that of self-sustainability. This is a topic focussed explicitly on policies and institutions and contains two nested levels of generality. The first level relates to the sustainability of the functioning of irrigation systems themselves. It is suggested that the matrix of institutions and incentives that control irrigation systems is, in many cases, the limiting factor in performance and that concern for sustainability should approach this constraint directly, as well as through new operational rules and technology.

The second level of generalit: is that of the whole of the change process. The longer range "solution" to the problem of sustainability is the developmc $t$ of a set of institutions which work together to provide the capacit to deal with change--assessing and evaluating evolving situation, and problems and developing solutions to them. 
The third area of concern is the interaction of irrigation with the physical resource base. This set of issues comprises those most traditionally associated with problems of sustainability in irrigation--waterlogging, salinization, and reservoir siltation. And while this clearly represents a lis t of most pressing problems, it is likely that to develop and implement solutions to them, the net must cast more broadly to include the second issue area above as well. Purely technical solutions are often enormously expensive and have associated with them the same kinds' - operational problems that help to generate the environmental problens in the first place.

We are right to be concerned with the sustainability of irrigated agricultural systems. The prot are real and imediate. The challenge is to be clear-eyed and $c$ :tive enough in specifying and analyzing those problems that we can distinguish between their symptoms and their causes. 